\title{
RESEÑA DE TESIS DOCTORALES
}

FERNANDO SOTELO RAFFO

Director académico del área de Ciencias de la UPC

\section{LA GESTIÓN POR PROCESOS EN SU PAPEL DE ESTRATEGIA GENERADORA DE VENTAJA COMPETITIVA APLICADA A LOS ENFOQUES DE ASOCIATIVIDAD DE LAS MYPES : CASO PERUANO}

La tesis doctoral tiene por objetivo desarrollar un sistema básico de gestión que haga que las Mypes de los cuatro sectores productivos más importantes de la economía peruana puedan enfrentar pedidos grandes. El sistema de gestión propuesto se basa en gestión por procesos, se propone el desarrollo de seis procesos según la importancia dada a ellos por los empresarios. Los procesos son: Gestión de la Calidad Total, Estandarización de procesos productivos, Gestión de pedido, Estandarización de producto, Planeamiento y Control de la Producción y Gestión Logística. Se ha desarrollado un estudio sobre el sector de manufactura el cual incluye el sector textil, maderero, metalmecánico y calzado, ya que estos cuatro sectores contribuyen en más del 50\% del PBI nacional y son productos exportables a los mercados internacionales.

El objetivo de la investigación es proponer un modelo básico de gestión de procesos que pueda ayudar a las Mypes a enfrentar con éxito la manufactura de un pedido grande asociándose de alguna forma. Este trabajo propone que la asociación sea a través de un sistema de procesos que hagan que cada Mypes pueda confiar en las demás y así trabajar de forma conjunta para obtener un producto estándar con las especificaciones de calidad requeridas por el cliente.

Se ha hecho un diagnóstico de los sectores Mype antes mencionados que serán capaces de exportar. Este diagnóstico se ha logrado a través de entrevistas en profundidad a 489 representantes de pequeñas y micro empresas. Este estudio se ha hecho con la finalidad de verificar las condiciones de gestión de sus empresas y poder diseñar los procesos que les puedan ayudar a gestionarse mejor independientemente y a la vez a constituir asociaciones mucho más confiables con la finalidad de poder enfrentar el requerimiento de un pedido grande (de exportación).

Luego de realizado el diagnóstico se procedió a el planteamiento del sistema básico de gestión. Este sistema básico está ligado a lo que las Mypes reconocen como los procesos principales de su cadena de valor, estos son los de producción, logística, estandarización de proceso y de producto, de calidad y el de gestión de pedidos. Estos procesos han sido caracterizados completamente, es decir, cada proceso tiene un mapa de procesos que establece todos los sub procesos necesarios, un flujograma de cada sub proceso, un SIPOC, un procedimiento y los indicadores de gestión correspondientes. Estos están detallados en los anexos 1,2, 3, 4,5 y 6. Los procesos han sido validados a través de casos de éxito, de literatura pertinente y a través de la implementación en una empresa pequeña.

Finalmente se presentan tres líneas de investigación que podrían proseguir de la presente investigación. Se establece pertinente que la investigación de este tema sea llevada hacia los servicios y hacia las medianas empresas para poder determinar modelos de éxito y asegurar su supervivencia en el tiempo.

\section{GUILLERMO TOMÁS QUIROGA PERSIVALE}

Director de la Escuela de Postgrado de la UPC

\section{IDENTIFICACIÓN DE PATRONES DE INNOVACIÓN ESTRATÉGICA A TRAVÉS DE NUEVOS MODELOS DE NEGOCIO EN UNA ECONOMÍA EN DESARROLLO. CASOS DE BUSINESS INNOVATION EN PERÚ CON IMPACTO GLOBAL}

En esta investigación el autor tiene como propósito identificar patrones en la innovación tecnológica, empleando nuevos modelos de negocio, dándolos a conocer y proponiendo su empleo como herramienta para futuros procesos estratégicos empresariales en un entorno competitivo.

Se presenta un amplio y relevante marco teórico que sirve como útil referencia a las propuestas de investigación, utilizando diversas herramientas como mapas bibliométricos, matrices de innovación para ilustrar la manera como se da el balance entre el empleo de la tecnología y el respectivo modelo de negocio, entre otras. Además, se incluyen ejemplos ilustrativos de empresas innovadoras estratégicas de diversos sectores favoreciendo la comparación por ramo entre competidor dominante. competidor tradicional e innovador estratégico.

En este trabajo se desarrollan propuestas a manera de hipótesis. Al respecto, se plantea que para lograr innovaciones de negocio, la alta dirección empresarial debe superar barreras mentales y de sus propios espacios o entornos, elevando, de esta manera, su escala o ámbito de pensamiento. Debe ser una gerencia proactiva hacia la innovación, dedicando tiempo y recursos a esta, en los 
niveles requeridos evitando de esta manera posturas conservadoras. Al respecto, se plantea que las empresas visionarias y prospectivas son las más dispuestas a la innovación y cuando esta se logra se desarrolla una posición competitiva diferente y mejor para competir en el nuevo entorno global.

Para poner en evidencia estas ideas, el autor aplica un enfoque cuantitativo, empleando modelos como el Business Model Canvas, al análisis de cuatro casos concretos, los cuales son Kola Real, AgroKasa, Grupo Interbank y Gastón Acurio. Al respecto, el caso de los hermanos Añaños, con Kola Real, es tenido en cuenta por la gran relevancia internacional que ha tenido al haber roto el paradigma tradicional de la manera de competir en el rubro de los refrescos, siendo, por esto, frecuentemente considerado como ejemplo de innovación en mercados emergentes. Por otro lado, Agrokasa es tenida en cuenta por su relevancia como moderna empresa agro exportadora que ha contribuido notablemente al desarrollo agrícola del departamento de Ica, primero con los espárragos y luego con las paltas. Luego se toma en cuenta el caso de Interbank que, siendo el cuarto banco más grande del Perú, ha tenido importantes logros en materia de innovación, por lo que ha merecido constantes participaciones en el Premio de Creatividad Empresarial. Finalmente, el caso de Gastón Acurio por el impacto generado debido a su aporte innovador, no solo como empesario de restaurantes, sino por el efecto multiplicador que este personaje ha ocasionado, en el desarrollo del rubro, en el empleo, en el turismo y por ende en el logro del sitial que actualmente ostenta la gastronomía peruana, tanto así como para afirmar que ha marcado un hito porque una cosa muy distinta ha sido antes y otra después de su aparición en escena.

La tesis concluye con abundantes referencias bibliográficas, las cuales no solo respaldan las aseveraciones de la investigación sino que además son una invitación constante a la lectura sobre el tema, continuando de esta manera la función exploratoria. 